\title{
Nuclear regulators to investigate 'contamination' incident at MIT
}

Washington. A post-doctoral fellow at the Massachusetts Institute of Technology (MIT) claims to be suffering from "pain all over [his] body" two months after an incident in the laboratory of Nobel laureate Susumu Tonegawa in which he appears to have ingested over 500 microcuries of the radioactive isotope phosphorus-32.

So far the incident, which took place on 14 August, has been kept quiet by MIT. But a team of inspectors from the Nuclear Radiation Commission (NRC) was expected to visit Tonegawa's laboratory this week to investigate it; the NRC says it was first notified of what happened by MIT on Monday, after the institute had been informed that Nature planned to report on it today.

A statement from MIT, which did not identify the researcher - Yuqing Li - or the laboratory at which the incident took place, said that it "had exposed the researcher to an intake of about 579 microcuries of radioactive material," noting that this is "within the permissible one-time and annual limit of 600 microcuries".

The statement said that the researcher had been examined by the medical department, and was released to go home. He had been re-examined "a number of times", and "no physical health effects were noted". It added that the short half-life of phosphorous- 32 meant that the amount of radioactive material in his body was now down to about 9 microcuries.

Six hundred microcuries of phosphorous32 is equivalent to $5 \mathrm{rem}$, the dose at which MIT would be required by law to notify the NRC of the incident within 24 hours - a process which will normally make the incident public. One of the first tasks of an inspector, says an NRC official, would be to check what he called MIT's "claim" that the

\section{NASA struggles to save Jupiter data}

Washington. Engineers at the National Aeronautics and Space Administration's (NASA's) Jet Propulsion Laboratory in Pasadena, California, are working overtime in a frantic effort to understand an apparent problem with the Jupiterbound Galileo spacecraft that could jeopardize the whole scientific return from the mission.

Telemetry data that were received last Wednesday (11 October) revealed that an onboard tape recorder, which will be used to store images and other data during Galileo's two-year tour of the Jupiter system, failed Galileo: malfunctioning tape recorder could to stop after rewind- seriously limit success of planet mission. ing. Mission managers immediately put the recorder in "safe" mode and began studying the problem using an identical recorder on the ground.

The apparent failure followed a picturetaking sequence in which the spacecraft had taken three separate images of Jupiter, each using a different colour filter. The images were the first to be recorded on tape since a newly uploaded sequence of software commands came into operation on 9 October.

The failure of the tape recorder would be a serious blow to the Galileo mission, which is already suffering the loss of a high-rate antenna that refused to unfurl properly four years ago. Project managers claim they can achieve almost threequarters of Galileo's original science objectives by using a smaller antenna to send back digital pictures and other data at a much slower rate, namely 160 bits per second rather than 134,000 bits per second.

But that strategy depends heavily on storing data collected during close encounters with the planet and its moons, and playing it back later. The recorder, which has a capacity of 109 megabytes, is the only one on board the spacecraft.

The Galileo orbiter and a smaller atmospheric probe will both arrive at Jupiter on 7 December. The probe will plunge into the cloud tops, recording information on the pressure, temperature and composition of the atmosphere as it descends. At about the same time, the orbiter will fire retro-rockets that will slow it sufficiently to orbit around the planet.

At the beginning of the week, the precise nature of the recorder's failure remained unknown. Project engineers were planning to begin sending commands to the spacecraft by the end of the week, in the hope that this will shed further light on the problem.

Tony Reichhardt dose was indeed 579 microcuries.

The dose estimate suggests that Li swallowed at least half the contents of a standard laboratory vial of phosphorous-32. That is at least ten times the amount used for a typical trace experiment, and enough to make accidental contamination extremely unlikely. MIT says its own investigations, conducted by it Radiation Protection Office and the MIT campus police, have been "unable to determine whether the radioactive material intake was deliberate or accidental".

Speaking from home, where he has been resting since the incident was discovered on 19 August, Li said that he had been in considerable physical pain since then. The Chinese researcher would not say if he was happy with the MIT investigation, or reveal any plans to seek redress. But sources close to Tonegawa's laboratory say that $\mathrm{Li}$ is considering legal action.

Tonegawa, who won the Nobel Prize in physiology or medicine in 1987 for his work in characterizing the T-cell receptor, declines to comment on the incident. He has a reputation for bringing an intensely competitive approach to his laboratory, which specializes in neurobiology as well as immunology.

MIT said its Radiation Protection Office "took control of radioactive substances in the laboratory" for nine days after the incident was discovered, and that "the laboratory has continued to operate every day". But scientists in the field say it would be difficult for the laboratory to operate effectively without the radioactive tracers, and it may face more disruption with the arrival of the NRC inspection team this week.

Victor Dricks, a spokesman for the NRC regional office at King of Prussia, Pennsylvania, which oversees MIT, said the NRC was uncertain whether business as usual could continue at the laboratory. "That's one of the things we're going to check out," he said.

NRC officials appear to be irritated that the institute failed to inform it about an incident that fell within a hairsbreadth of a legal reporting requirement. Until a few months ago, when a previous regulation was withdrawn, MIT would have bcen obliged to file a written report within 30 days for a dose one-quarter of that ingested by $\mathrm{Li}$.

Colin Macilwain

Federal investigators are studying the circumstances under which a group of researchers at the National Cancer Institute in Bethesda, including a pregnant research fellow, appear to have been deliberately contaminated with the radioisotope P-32.

For details, see page 568. 